\title{
Librarians' competency and willingness towards serving the users with disabilities: where do Sri Lankan librarians stand?
}

Wijayaratne, Anusha ${ }^{1}$ and Amarasekara, Ramani ${ }^{2}$

\begin{abstract}
This paper presents the findings of a survey that aims at exploring the potential of Sri Lankan library professionals for serving the disabled users. Results revealed that the librarians are not adequately knowledgeable and sufficiently skilled to operate an inclusive service for people with special needs, though, they are extremely willing to do so. The paper also discusses the areas that should be strengthened in order to empower the librarians while highlighting the necessity of broadening the boundaries to welcome this very special group of users.
\end{abstract}

Keywords: Library uses for disabled people, Disabled library users, Library services Sri Lanka

\section{Introduction}

Protecting the rights of disabled people is not a new topic even to developing countries like Sri Lanka. However, we are far behind our developed counterparts such as United States of America (USA) and United Kingdom; the countries that could be easily topped the list of nations who pay the most attention towards their disabled citizens. Americans with Disabilities Act (ADA) that addresses the needs of people with disabilities of USA has characterized disabled people as "individuals with a physical or mental impairment that substantially limits one or more of the major life activities". Meanwhile, Equality Act 2010 of the United Kingdom also has described disabled people with more or similar terms; "persons with a physical or mental impairment that has a 'substantial' and 'long-term' negative effect on their ability to do normal daily activities". The rights of the disabled Sri Lankans too have been protected by the law. The National Policy on Disability for Sri Lanka (2003) declares that "They will have opportunities for enjoying a full and satisfying

\footnotetext{
Corresponding Author:

${ }^{I}$ Senior Assistant Librarian, Open University of Sri Lanka, Sri Lanka.Email: idwij@ou.ac.lk

${ }^{2}$ Deputy Librarian, Open University of Sri Lanka, Sri Lanka. Email: rmar@ou.ac.lk
} 
Journal of the University Librarians Association of Sri Lanka, Vol.18, Issue 1, January 2014

life and for contributing to national development ... as equal citizens of Sri Lanka". However, there are only a few visible signs to indicate that the physical and intellectual needs of the disabled people are being properly looked after in our society. It is essential to take immediate steps to create a barrier free environment in order to persuade the disabled people to come out of their homes to join the workforce of the country. Besides, an attitudinal change in the society (inclusive of both disabled and abled community) is essential to convert a dependant disabled person, who used to live under the protection and care of the family and friends, into an empowered individual.

Under these circumstances, libraries have a vital role to play particularly, in meeting the intellectual needs of the disabled community, inclusive of people with various physical challenges such as blindness, low vision, hearing difficulties, mobility problems, plus people with mental challenges. However, establishing a disability-friendly environment is an enormous challenge for Sri Lankan librarians who are already under pressure due to the declining budgets in the face of escalating costs of library materials and equipment. Hence, most of the Sri Lankan libraries have miserably failed to provide an equal level of service to ALL the readers. This issue is not only common to the developing countries in Asia and Africa but researchers (Copeland, 2009; Koulikourdi, 2008a; Koulikourdi, 2008b; Beaton, 2005; McCaskill \& Goulding, 2001) who represent the Western world, had also stated that their libraries are not properly built or fully equipped to serve the disabled users. In other words, many librarians, in spite of their location in the globe, are abandoning a large number of prospective users. However, as pointed out by Koulikourdi (2008b) at least some of these libraries, who fail to practice their duties due to lack of interest or unawareness, have the potential in terms of skills and resources to establish the fundamental requirements for fulfilling the special needs of disabled users. In addition, there are inexpensive alternative methods to accommodate the disabled users. For example, if the library is unable to install elevators or ramps to allow the wheelchair users to reach the materials, then the library should assign volunteers to bring the materials to the disabled users. Some way or other, it is essential for the librarians to serve the disabled users in order to make 
Journal of the University Librarians Association of Sri Lanka, Vol.18, Issue 1, January 2014

sure that they are performing their distinguished duty of protecting the intellectual freedom of mankind.

In today's standard, designing barrier-free library websites is equally, if not more, important as constructing an accessible physical environment in libraries, since modern libraries exclusively depend on the web channel for delivering resources and services. Besides, the library website is an excellent tool to reach the home-bound users with mobility problems. Further, designing and maintaining a barrier-free website is much easier and cheaper than constructing a barrier-free physical environment. However, as reflected in the literature, the library web designers pay very little attention towards designing websites, free of accessibility errors. Numerous researchers, including Axel Schmetzke who had conducted library website accessibility evaluation studies from 1999 to 2005 at the University of Wisconsin campuses (details of these studies can be viewed from http://library.uwsp.edu/aschmetz/Accessible/websurveys.htm), Wijayaratne and Singh (2010), Wijayaratne (2008) and Craven (2002) have pointed out that librarians are slow to respond towards the demand for accessible library websites.

\section{Rationale of the study}

In spite of the abundance of good practices in serving the disabled users around the world and growing discussions on universal access philosophy, very little have been said or done within the Sri Lankan context except the two recent studies, namely Wickramasinghe (2012) and Wijayaratne and Amerasekara (2011). Both these studies have disclosed that the Sri Lankan libraries are in need of enhancing the libraries in terms of infrastructure facilities, equipment and services in order to accommodate this special group of users.

This study has been carried out as an extension of the authors' 2011 study that measured the readiness in libraries to serve the people with various physical challenges (i.e. blindness, low vision, hearing difficulties, mobility problems) in terms of four parameters namely; provision for physical access; availability of appropriate facilities, resources and services; and provision for web access. The study reveals that readiness of the libraries was far below the satisfactory level in all the measured parameters. The findings also indicate 
that insufficient knowledge and skills of the staff is one of the major obstacles in establishing exclusive services for disabled Sri Lankans. In other words, librarians' incapability in identifying and addressing the needs of disabled users promptly and appropriately has been denoted as a decisive bottleneck in the process of designing and implementing services for disabled users in Sri Lanka.

As Charles (2005) pointed out, libraries can significantly upgrade the quality of front-line services delivered to disabled users through training programs that have been developed with clear, practice-oriented values in mind. Therefore, empowering the librarians through appropriate teaching and training programs should come first in the agenda in order to uplift library services for disabled Sri Lankans. The findings of this current study produce a comprehensive data set on the current level of competency and the level of willingness of Sri Lankan library professionals towards serving the disabled users and highlight the areas that should be strengthened in order to empower the librarians for mastering this service component.

Data produced by the study would be useful for Sri Lankan LIS educators who involve in designing theoretical and practical modules on disability library services. Besides, it is also expected to persuade the librarians to empower themselves through exploring the literature and participating in seminars and workshops. Further, encouraging the librarians to re-visit their attitudes in the light of growing demand for universal access is also among the intentions of the study.

\section{Objectives of the Study}

- Determine the level of competency of Sri Lankan librarians in respect of serving the disabled users.

The level of competency has been measured in 21 parameters of three dimensions namely; awareness of related aspects on disability library services (5), knowledge and skills on disability library services (8), knowledge and skills on web accessibility (8). 
- Determine the level of willingness of Sri Lankan librarians towards serving the people with disabilities.

The level of willingness has been measured through 10 statements that have been formulated in a manner to identify the methods and sources used by the participants to gain the knowledge or practice the skills.

\section{Methodology}

In order to achieve the above objectives, following tools and techniques have been used to collect and analyze the data.

\section{Research Method and Population}

The survey method was selected for the study since it allows collecting data from professionals scattered throughout the country. There were 244 chartered librarians included in the List of Corporate Members published by the Sri Lanka Library Association (http://www.slla.org.lk/) in 2011. The target population has been calculated as 220 (approximately) after deducting 10\% for the retired librarians.

\section{Research Instrument}

The research instrument used for the study is a questionnaire designed through a process of self-evaluation and peer comments. Apart from the geographical information, the questionnaire consisted of four sections namely, awareness of related aspects on disability library services; knowledge and skills on disability library services; knowledge and skills on web accessibility and accessible web designing; willingness towards serving the people with disabilities.

\section{Study Sample and Data Collecting Process}

Due to time and budget limitations of the project, it was decided to distribute the survey questionnaire through the "Sri Lanka Library Friends". It is the most popular e-mail group among the library professionals of Sri Lanka and believed to be consisted of at least $50 \%$ of 
the target population, which is approximately 220. Hence, the size of the sample selected for the study is approximately 110 , a $50 \%$ of the population.

Firstly, the questionnaire was published in the Open University of Sri Lanka (the employer of the authors) library website and then the link was published in the "Sri Lanka Library Friends" together with a covering e-mail requesting the participation from all library professionals. To increase the number of responses, three friendly reminders have been sent at two week intervals.

\section{Data Analysis Techniques}

Data was analyzed using Microsoft Excel 2007.

The formula used to calculate the level of competency (X) and the level of willingness (Y) as follows.

$\mathrm{X}=$ no. of positive hits*/total number of hits $\mathrm{X} 100$

$$
X=X_{p} / X_{t} \times 100
$$

$\mathrm{Y}=$ no. of positive hits*/total number of hits $\mathrm{x} 100$

$$
\mathrm{Y}=\mathrm{Y}_{\mathrm{p}} / \mathrm{Y}_{\mathrm{t}} \mathrm{x} 100
$$

Note* - number of participants said 'yes' to the statements

\section{Findings of the Study}

Key finding of the study is presented in this section using tables and figures for illustrating the results on par with the objectives of the study.

\section{Response Rate}

Number of responses received during the three month survey period $(15 / 03 / 2012$ $15 / 06 / 2012$ ) is 40 and the rate of response is approximately $36 \%$. 
Journal of the University Librarians Association of Sri Lanka, Vol.18, Issue 1, January 2014

\section{Profile of the Participants}

Out of the total number of 40 participants, 27 (67.5\%) were females. Since the Sri Lankan LIS field is mainly female dominated, the high response recorded from the female participants was expected. Majority (55\%) of participants have more than 10 years of experience while $32.5 \%$ of participants have 5-10 years. Another significant characteristic of the participants is their sound educational qualifications. All the participants have at least a bachelor's degree or higher qualifications (i.e. $22.5 \%$ of them possess a bachelor's degree and $77.5 \%$ have either a master's degree or a postgraduate diploma, in addition to the bachelor's degree). Figure 1 illustrates the findings.

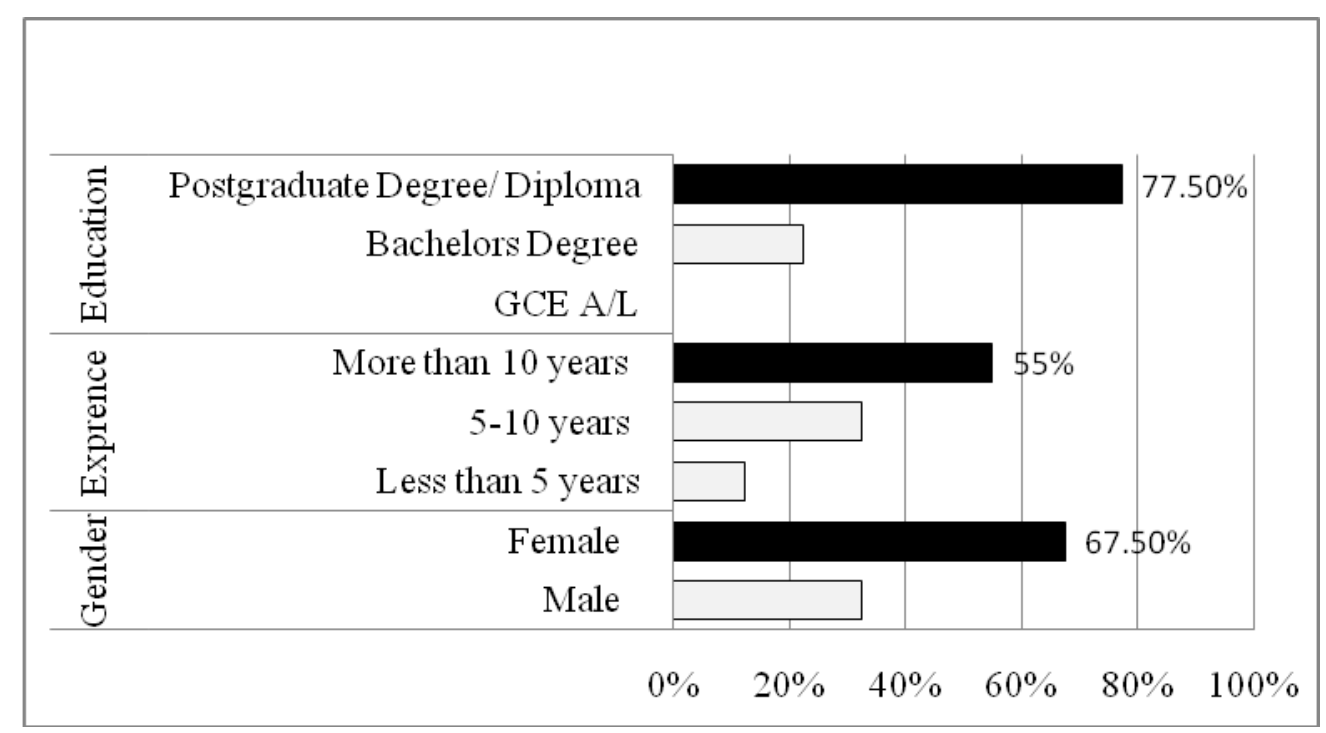

Figure 1: Profile of the participants

As shown in the Figure 1, the participants of this study are a set of very well experienced librarians with sound educational backgrounds.

\section{Competency of Librarians in Respect of Serving the Disabled Users}

Level of competency $(\mathrm{X})$ of librarians was measured in terms of the following three dimensions, namely; 
Journal of the University Librarians Association of Sri Lanka, Vol.18, Issue 1, January 2014

- Level of awareness of related aspects on library services for people with disabilities (Xa)

- Level of knowledge and skills on library services for people with disabilities $(\mathrm{Xb})$

- Level of knowledge and skills on web accessibility and accessible web designing $(\mathrm{Xc})$

\section{Level of awareness of related aspects on disability library services}

The level of awareness of related aspects on library services for disabled users was measured through five statements. Number of participants answered 'Yes' to the five statements were taken as positive hits. All the five statements scored values less than $40 \%$ as shown in Table 1.

Table 1: Awareness of related aspects on disability library services

\begin{tabular}{|l|r|r|}
\hline Statements & $\begin{array}{c}\text { Positive hits } \\
\left(\mathrm{Xa}_{\mathrm{p}}\right)\end{array}$ & $\begin{array}{l}\text { Level } \\
(\mathrm{Xa})\end{array}$ \\
\hline I am aware of alternative formats of resources & 14 & $35 \%$ \\
\hline I am aware of assistive technologies & 11 & $28 \%$ \\
\hline I am aware of different types of disability services & 10 & $25 \%$ \\
\hline I am aware of physical accessibility features & 11 & $28 \%$ \\
\hline I am aware of web accessibility features & 3 & $8 \%$ \\
\hline $\begin{array}{l}\text { Level } \text { of } \text { awareness } \text { of related aspects } \text { on disability library } \\
\text { services }(\boldsymbol{X} \boldsymbol{a})\end{array}$ & $\mathbf{4 9}$ & $\mathbf{2 5 \%}$ \\
\hline
\end{tabular}

Level $\mathrm{Xa}=\mathrm{Xa}_{\mathrm{p}}(49) / \mathrm{Xa}_{\mathrm{t}}(5 \times 40) \times 100$

The statement, 'I am aware of alternative formats of resources' reported the highest percentage of $35 \%$, while the statement 'I am aware of web accessibility features' reported just $8 \%$, which is the lowest. Consequently, the level of awareness of related aspects on disability library services $(\mathrm{Xa})$ remained at $25 \%$.

\section{Level of knowledge and skills on disability library services}

The level of knowledge and skills on library services for disabled users was measured through eight selected statements. The statements were formulated in a manner to identify 
Journal of the University Librarians Association of Sri Lanka, Vol.18, Issue 1, January 2014

the methods and sources that were used by the participants to gain the knowledge or practice the skills.

Number of participants answered 'Yes' to the eight statements were taken as positive hits.

Table 2 presents the results.

Table 2: Knowledge and skills on library services for disabled users

\begin{tabular}{|l|l|l|}
\hline Statements & $\begin{array}{l}\text { Positive hits } \\
\left(\mathrm{Xb}_{\mathrm{p}}\right)\end{array}$ & $\begin{array}{l}\text { Level } \\
(\mathrm{Xb})\end{array}$ \\
\hline $\begin{array}{l}\text { I have studied 'library services for disability' as a part of a library } \\
\text { educational program (diploma, bachelor's degree, master's etc. })\end{array}$ & 13 & $33 \%$ \\
\hline $\begin{array}{l}\text { I have learned about this theme through informal communication } \\
\text { with friends and professional colleagues }\end{array}$ & 37 & $93 \%$ \\
\hline I have participated at least one conference/ seminar on this theme & 2 & $5 \%$ \\
\hline I have got in-house training on this theme & 3 & $8 \%$ \\
\hline $\begin{array}{l}\text { I have participated at least one outside workshop/ training program } \\
\text { on this theme }\end{array}$ & 3 & $8 \%$ \\
\hline I have read at least one scholarly article on this theme & 33 & $83 \%$ \\
\hline I have written at least one scholarly article on this theme & 1 & $3 \%$ \\
\hline I have conducted at least one study on this theme & 1 & $3 \%$ \\
\hline $\begin{array}{l}\text { Level of } \boldsymbol{k n} \text { ewledge and skills on library services for disabled } \\
\text { users }(\boldsymbol{X b})\end{array}$ & $\mathbf{9 3}$ & $\mathbf{2 9 \%}$ \\
\hline
\end{tabular}

Level $\mathrm{Xb}=\mathrm{Xb}_{\mathrm{p}}(93) / \mathrm{Xb}_{\mathrm{t}}(8 \times 40) \times 100$

Only $33 \%$ of the participants had learned the disability library services through educational programs while $93 \%$ of them had learned (or at least heard about) through informal communication. The statement, 'I have read at least one scholarly article on this theme', scored the second highest value, which is $83 \%$. The rest of the five statements reported values less than $10 \%$.

Similar to the level of awareness of related aspects $(\mathrm{Xa})$, which is just $25 \%$, the level of knowledge and skills (Xb) also reported a value below $30 \%$, which is $29 \%$. 


\section{Level of knowledge and skills on web accessibility and accessible web designing}

The level of knowledge and skills on web accessibility and accessible web designing was measured through a set of eight selected statements.

Number of participants answered 'Yes' to the statements were taken as the positive hits.

The findings are given in Table 3.

Table 3: Knowledge and skills on web accessibility and accessible web designing

\begin{tabular}{|l|l|l|}
\hline Statements & $\begin{array}{l}\text { Positive } \\
\text { hits }\left(\mathrm{Xc}_{\mathrm{p}}\right)\end{array}$ & $\begin{array}{l}\text { Level } \\
(\mathrm{Xc})\end{array}$ \\
\hline $\begin{array}{l}\text { I have studied 'web accessibility/ accessible web designing' as a } \\
\text { part of a library educational program (diploma, bachelor's degree, } \\
\text { master's etc.) }\end{array}$ & 3 & $8 \%$ \\
\hline $\begin{array}{l}\text { I have learned about this theme through informal communication } \\
\text { with friends and professional colleagues }\end{array}$ & 32 & $80 \%$ \\
\hline I have participated at least one conference/ seminar on this theme & 2 & $5 \%$ \\
\hline I have got in-house training on this theme & 3 & $8 \%$ \\
\hline $\begin{array}{l}\text { I have participated at least one outside workshop/ training program } \\
\text { on this theme }\end{array}$ & 2 & $5 \%$ \\
\hline I have read at least one scholarly article on this theme & 24 & $60 \%$ \\
\hline I have written at least one scholarly article on this theme & 0 & $0 \%$ \\
\hline I have conducted at least one study on this theme & 0 & $0 \%$ \\
\hline $\begin{array}{l}\text { Level of } \text { knowledge and skills on } \text { web accessibility and accessible } \\
\text { web designing }(X \boldsymbol{c})\end{array}$ & $\mathbf{6 6}$ & $\mathbf{2 1 \%}$ \\
\hline
\end{tabular}

Level $X c=\mathrm{Xc}_{\mathrm{p}}(66) / \mathrm{Xc}_{\mathrm{t}}(8 \times 40) \times 100$

Six statements that used to measure knowledge and skills on web accessibility scored below $10 \%$, though, the rest of the two statements - 'I have learned about this theme through informal communication with friends and professional colleagues' and 'I have read at least one scholarly article on this theme' - scored $80 \%$ and $60 \%$ respectively.

The level of knowledge and skills on web accessibility $(\mathrm{Xc})$ was reported the lowest value ( $21 \%$ ) out of the three dimensions that determine the level of competency of librarians in respect of serving the disabled users. 


\section{Willingness to Serve the People with Disabilities}

The level of willingness to serve the people with disabilities $(\mathrm{Y})$ was measured through the following nine statements.

- I believe it is my social and professional obligation to serve people with disabilities.

- I believe that the outside of the library building, entrance and inside of the library should be designed in a way that could be easily accessed by people with disabilities.

- I believe that the library should provide appropriate toilet facilities for disabled users.

- I believe that the library should provide sufficient seating facilities with appropriate furniture and lighting system for disabled users.

- I believe that the library should have a specialized signage system for disabled users.

- I believe that the library should develop and maintain a sufficient collection of alternative formats of resources and necessary assistive device.

- I believe that the library should train their staff and make procedural changes to accommodate the diverse needs of disabled users.

- I believe that library website should be designed in accordance with web accessibility guidelines to enhance the accessibility of disabled users.

- I am very happy to cooperate towards any activity that is aimed at introducing/expanding library services for disabled users.

Number of participants answered 'Yes' to the above statements were taken as positive hits. All the participants answered 'Yes' to all the statements. Hence, the level of willingness to serve disabled users has reached its maximum (100\%).

\section{Discussion}

Findings of this study helped to develop a good understanding on the ability and attitudes of librarians towards serving the disabled users. The competency was measured altogether 
Journal of the University Librarians Association of Sri Lanka, Vol.18, Issue 1, January 2014

in 21 parameters - awareness (5), knowledge and skills on library services for disability (8), knowledge and skills on web accessibility (8). The total number of positive hits received for all 21 parameters was only 208 out of the total number of 840 (21 x 40) hits. Therefore, the level of competency has just managed to reach $25 \%$. Figure 2 illustrates the competency level $(\mathrm{X})$ together with the levels of its three dimensions ( $\mathrm{Xa}, \mathrm{Xb}, \mathrm{Xc}$ ) that combine to determine the competency level of the librarians.

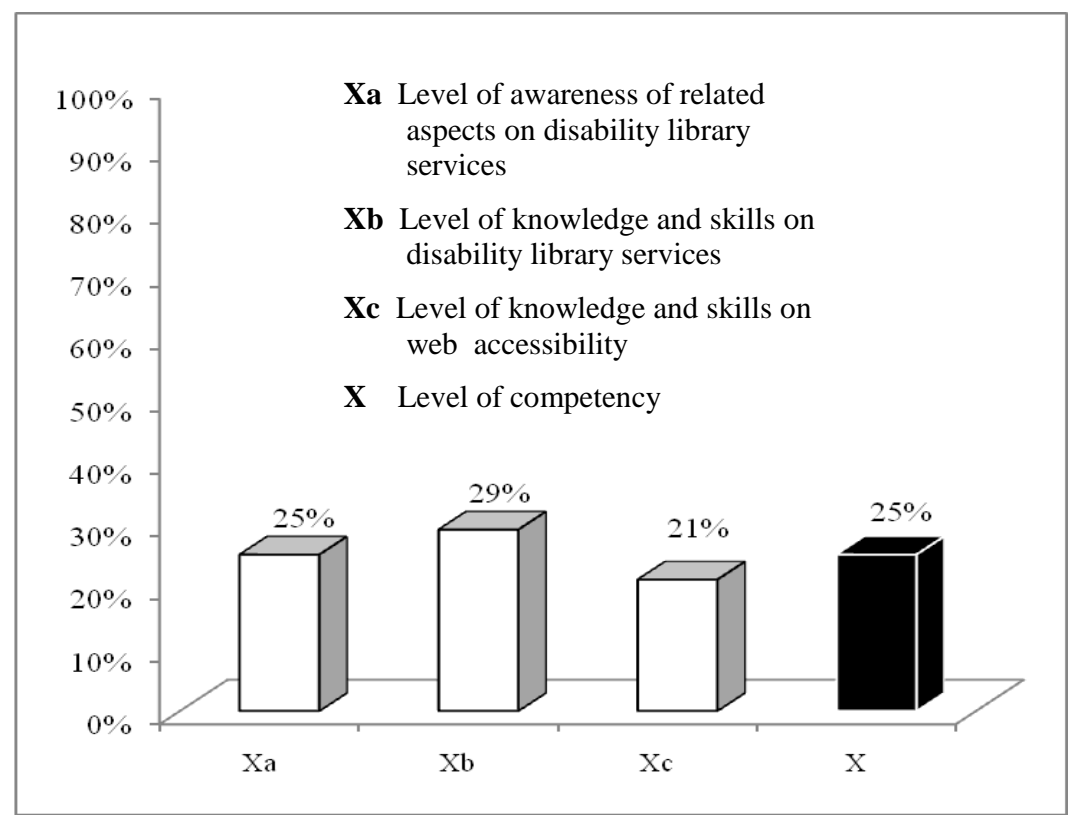

Figure 2: Level of competency of Sri Lankan librarians towards serving the disabled users

It is clear that there is not much of a difference among the different dimensions of competency. However, each column carries certain important messages to Sri Lankan librarians and LIS educators.

The low level of awareness of related aspects on disability library services (Xa) demands immediate actions to enhance the awareness on appropriate resources, services and equipment among the Sri Lankan librarians. Talks by invited experts and in-house workshops may help a lot to raise awareness among the professional and para-professional 
Journal of the University Librarians Association of Sri Lanka, Vol.18, Issue 1, January 2014

staff. Librarians also could be benefited from the wealth of literature and online and offline platforms that exclusively discuss topics related to disability library services.

The level of knowledge and skills on disability library services $(\mathbf{X b})$ is the best out of the three dimensions measured, but when numerically presented it is at meager value of $29 \%$. The inability of Sri Lankan LIS education system in preparing professionals to serve ALL users, is quite apparent when looking at the small percentage of participants (33\%) who had gained the knowledge through formal education systems. All 13 (33\%) participants who had declared that they have learned disability library services as a part of the library education program also have mentioned that they have learned it through informal communication as well. This means that $24(60 \%)$ participants have learned the topic only through informal communication while three participants have mentioned that they do not have any kind of exposure in this regard.

The level of knowledge and skills on web accessibility and accessible web designing (Xc) is the lowest of all and seems to be receiving the least attention from the Sri Lankan librarians. Out of the eight statements, two have received zero positive hits and only three participants (out of the 40) have claimed that they have learned web accessibility during their formal education system. Most probably they have got this exposure through some sort of a foreign education.

National Disability Policy of Sri Lanka (2003) does not include a section on web accessibility. This itself indicates the absence of interest towards the web accessibility in the Sri Lankan context as a whole. However, there is no argument that designing accessible websites is also one of the decisive factors, if not the most decisive, to ensure the intellectual freedom of the disabled citizens in the light of the upcoming e-society concept. Therefore, it is very much needed to initiate a dialog at the national level to gain the attention of policy makers in order to summon the due legal values to the subject. Librarians can play a vital role in this aspect and contribute towards lifting the barriers in 
Journal of the University Librarians Association of Sri Lanka, Vol.18, Issue 1, January 2014

the cyberspace for this special group of citizens, who are already suffering due to physical hindrances in the society.

Findings with respect to willingness of librarians towards serving the disabled users are quite the other way. Although, Sri Lankan librarians are found to be low in their competency level, they seem to be extremely willing (100\%) to perform their duties towards the disabled users. However, the possibility of high participation of LIS professionals who have an interest towards serving the disabled users may have an impact on this high willingness level. The comparison between the competency level (X) and willingness level (Y) is illustrated in Figure 3.

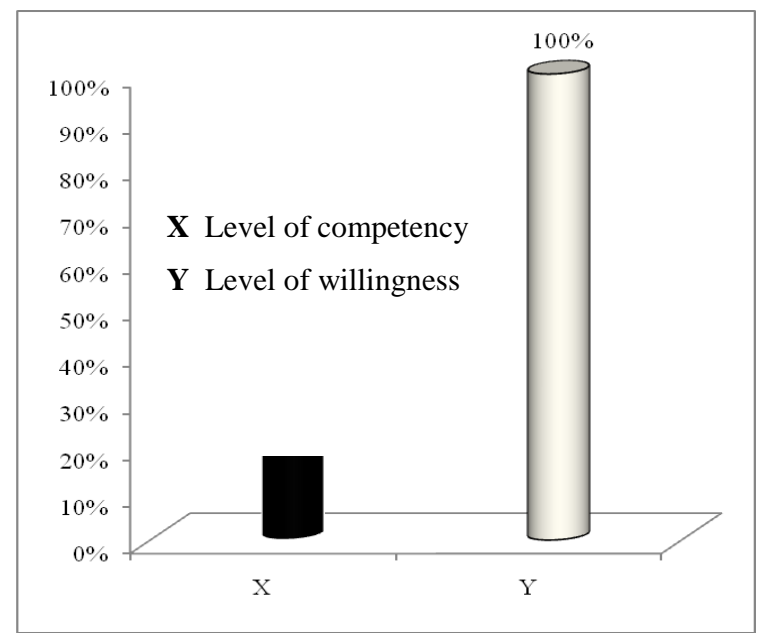

Figure 3: Levels of competency and willingness of Sri Lankan librarians towards serving the people with disabilities

It is hard to figure out the reasons for being so poor in competency level while at the same time being so keen to be of assistance to people with disabilities, particularly, when the participants happen to be a group of highly qualified and well experienced professionals. All the participants at least have a bachelor's degree or higher qualifications and over five years of experience in the LIS field. There are more than enough sources and channels for them to empower themselves even though they did not get an opportunity to learn the subject via the formal education systems. The authors believe that the reasons mostly lie on the cultural values of Sri Lanka, where the disabled and old aged people are treated as 
Journal of the University Librarians Association of Sri Lanka, Vol.18, Issue 1, January 2014

delicate individuals who should be taken care of, in a very close family environment, rather than as independent citizens. However, this attitude seems to be changing, yet very slowly. Both government and private sector institutions including libraries have begun to realize their responsibility towards opening doors for all citizens to create a society free of discriminations. The additional comments received for this survey (as listed below) are good indications of the new interest developing among the Sri Lankan librarians towards serving the disabled users.

Following is a brief account of additional comments made by the participants:

- This area of learning should be included in the library science curricula and some organization should conduct awareness programs for the librarians

- I have come across a research paper regarding the library services of wheelchair users. This research will help all librarians and administrators to think more on facilitating disabilities and to seek ways to enhance the services

- My congratulation for your new research. Please do it as soon as possible \& propose to SCOLIS (UGC - Standing Committee on LIS) to establish some facilities in University Libraries. Please contact Blind Prof: Weerakkody Dept. of Classical Language, University Peradeniya. He is an excellent library user. Also he is using modern technology for disabled readers and he is maintaining a Centre for Disabled Users at the University of Peradeniya.

- I have seen how the disabled are served at Central Library, New Zealand, Wellington. Wonderful service.

- Though we are very keen to serve the users with special needs at the University of Peradeniya, it is very difficult to meet the requirements with budgetary constraints and special problems. At the moment we are facing severe difficulties with space in the Main Library; for instance when shelving the Brail books, it needs substantial capacity of space than shelving of monographs in general format. Any how we try to overcome those issues in near future for the benefit of users with special needs. Good Luck!

- I am so happy that you have started on this topic. I wish you all the best. 
Journal of the University Librarians Association of Sri Lanka, Vol.18, Issue 1, January 2014

- Of course libraries should focus on providing services to disabled, however, the awareness of their needs, librarians' interests, finance, and other related issues exhibit obstacles to implement those services. Sometimes, the needs do not justify the investments on these services as the number of disabled is only 2-3 in my university.

\section{Concluding Remarks}

As Koulikourdi (2008a) pointed out, accommodating the diverse needs of disabled users is an on-going and long-term process that needs the continuous attention from the part of the librarians and authorities of their parent organizations. However, it is one of the areas that received the least attention from the Sri Lankan librarians until quite recently. As the findings have revealed, awareness; knowledge and skills of Sri Lankan librarians in this regard are at an extremely unhappy state. The main reason for this disappointed situation could be the lack of educational and training opportunities either through formal educational programs or in-house training. Besides, as Bonnici, Maatta and Wells (2009) have stated, human resources and information technologies are going to be the major challenges to the future of information access. Hence, authorities and Sri Lankan LIS educators should establish a proper mechanism for expanding the educational, training and familiarizing opportunities through activities such as integrating related topics to LIS curricula, conducting in-house awareness programs on disability services; organizing conferences and speeches, encouraging to conduct research studies on related topics etc. However, as any other growing field, the librarianship on disability services too needs a set of self-motivated and committed professionals who continuously explore, generate and implement in the field, in order to keep it alive and flourishing. 
Journal of the University Librarians Association of Sri Lanka, Vol.18, Issue 1, January 2014

\section{References}

Beaton, M. (2005). Glasgow city council: library, information and learning services for disabled people in Glasgow. Library Review, 54(8), 472-478.

Bonnici, L., Maatta, S. \& Wells, M. (2009). US national accessibility survey: Librarians serving patrons with disabilities. New Library World, 110 (11), 512-528.

Charles, S. (2005). Person first, disability second: disability awareness training in libraries. Library Review, 54 (8), 453-458.

Copeland, C. (2009). Library and information center accessibility: the differently-able patron's perspective. Proceedings of the American Society for Information Science and Technology, 46 (1), 1

Craven, Jenny. (2002). Electronic access for all: awareness in creating accessible Web sites for the university library. Available at:

http://www.dmag.org.uk/resources/casestudies/cravenfull.asp (accessed 12 March 2012).

National Policy on Disability for Sri Lanka (2003). Available at:

http://siteresources.worldbank.org/INTSRILANKA/Resources/NatPolicyDisability

Sep2003srilanka1.pdf (Accessed 12 March 2012).

Koulikourdi, A. (2008a). Assistive technologies in Greek libraries. Library Hi Tech, $26(3), 387-397$.

Koulikourdi, A. (2008b). Library services for people with disabilities in Greece. Library Review, 57 (2), 138-148.

McCaskill, K. \& Goulding, A. (2001). English public library services and the Disability Discrimination Act. New Library World, 102 (6), 192-206.

Wickramasinghe, K. (2012). Study of the problems of physically disabled people in using the public libraries. MLS thesis, National Institute of Library \& Information Science, University of Colombo.

Wijayaratne, A. (2008). Web accessibility: does it have a role in delivering distance education. Proceedings of 5th PAN Commonwealth Forum on Open Learning. Available at: http://wikieducator.org/images/d/d1/PID_159.pdf. (Accessed 12 March 
Journal of the University Librarians Association of Sri Lanka, Vol.18, Issue 1, January 2014 2012).

Wijayaratne, A. \& Amarasekara, R. (2011). Readiness in academic libraries to serve the disabled patrons. Proceedings of the 8th National Conference on Library and Information Science, 51-59.

Wijayaratne, A. \& Singh, D. (2010). Is there a space in the cyberspace for distance learners with special needs in Asia?: review of level of web accessibility of institutional and library homepages of AAOU members. International Information \& Library Review, 42 (1), 40-49. 